\title{
Innovative Talent Training Model to Actively Explore the Hierarchical Culture
}

\author{
Qigao $\mathrm{Hu}^{1, \text { a }}$, Peng $\mathrm{Hao}^{2, \mathrm{~b}}$, Weifeng $\mathrm{Cui}^{1, \mathrm{a}}$, Weihua $\mathrm{zhu}^{1, \mathrm{a}}$ \\ ${ }^{1}$ College of Basic Education for Commanding Officers, NUDT, Changsha, 410072, China \\ ${ }^{2}$ nstitute of Engineering Corps, Xuzhou, 221000, China \\ aemail: 13308492472@189.cn, bemail: 552099469@qq.com @163.com
}

\begin{abstract}
Keywords: talent training model; hierarchical culture; Tsien Hsueshen Innovation Development Class
\end{abstract}

\begin{abstract}
The competition of comprehensive strength between nations is fundamentally the competition of talents . To make a nation powerful, the firth thing is to improve higher education because cultivation of talents must depend on education. Similarly, to make an army powerful, education also should be strong firstly. The important mission of training of senior scientific and technical and commanding talents for the building of national defense and armed forces is undertaken by National University of Defense Technology. On the basis of analyzing the reason and significance of the hierarchical culture, combining the analysis of the research of "Tsien Hsueshen Innovation Development Class " of the university, the conclusion can be reached that the "Tsien Hsueshen Innovation Development Class" is new hierarchical culture model conformed to the law of personnel training objective and actual demand. Corresponding suggestions are put forward about the hierarchical culture and the construction of "Tsien Hsueshen Innovation Development Class " based on the research results.
\end{abstract}

\section{Introduction}

In the twenty-first century, competition between nations is essentially about talents, especially innovative talents. A country's development and international status are more and more determined by the knowledge innovation, the development of science and competition of talents. In many developed countries, the contribution rate of the progress of science and technology in economic growth was $5 \%-20 \%$ in early twentieth century. The rates were respectively $50 \%$ by the middle of the twentieth Century, $60 \%-80 \%$ to the 80 's and more than $80 \%$ of the proportion after 80 years[1]. The research report "learn to survive" in UNESCO also pointed out that "the ability of people to deal with global issues and challenges in the final analysis depends on human's creative potential that can be inspired and aroused[2]. To enhance our comprehensive national strength and international competitiveness, the State Council promulgated the "national long-term science and technology development plan" in 2006, which made the "independent innovation" as a guiding principle, and put the construction of an innovative country as a major strategy for the future. Innovation depends on talents. Development needs talents. Education plays an irreplaceable role in cultivating talents. The major task of higher education is to cultivate advanced talents, develop science and technology's culture and promote the construction of socialist modernization. The college very naturally becomes the main positions and the main channel to cultivate talents, especially for the significant responsibility in cultivating innovative talents. Power will be strong to teach first. So the education was still put in the priority development status in the 18th national congress of CPC report. And the standpoint of "speeding up the establishment of talent priority development strategy layout, creating large-scale quality of personnel, promoting our country by human power to talent" was clearly put forward.

\section{Hierarchical Training Talents}

In the "national medium and long-term educational reform and development plan (2010-2020)" 
"innovation talent training model", the requirements of teaching reform were put forward clearly to teach students in accordance with their aptitude, and promote hierarchical teaching. The ultimate goal of hierarchical teaching reform is hierarchical training of personnel, which is new model of a design for different students with different training objectives aim. The development of human resources was maximized by classification of talent cultivation.

Students are the future of the talents. As the subject of learning, the inevitable differences exist between students. Firstly the differences can not be avoided in intelligence due to different hereditary gene between students. Secondly it is in the foundation for learning. Each student's education is different. Even if they receive the same education, personal understanding degree is also different. The result will lead to differences between students' learning foundation. Furthermore, there are differences in learning quality because of each student's different learning attitude and efficiency. Because of the differences in the above three aspects, it very naturally leads to the distinguishing between the level of students, which is essential for students needing hierarchical education and is the fundamental basis of many educators who had proposed to teach students in accordance with their aptitude.

The source of hierarchical education came actually from China. As early as in the Spring and Autumn and the Warring States period, the famous thinker, educator, Confucius firstly put forward the thought of "make no social distinctions in teaching, teach students in accordance with their aptitude" about the talent cultivation, who also educated students "seeing their doing, watching its approach, observing its interest and hobbies." And once he thought his students were stupid, dull, extreme or reckless[3]. Thinker Mo-tse advocated to educate students according to the education object with different educational content, and set up different demand standards according to the students' qualification and ability. Bloom who is contemporary American famous psychologist and educator thinks that just giving each student appropriate materials and education, while providing appropriate help and sufficient time, almost all the students can complete the task of learning or specified target. Bloom's mastery learning theory provides the theoretical basis for hierarchical education theory[4]. The essence of hierarchical education is based on the respect and recognition of the individual differences of students. The ability of each student is developed from the reality. The advantage is that not only reflects the emphasis, but also can advance step by step and systemic manifestation.

Chinese expansion of enrollment in colleges and universities at the end of twentieth century, China's higher education came from elite education to mass education. The enrollment is rapid expanding and the average quality of students is dropping. A unified training target is set up in the same major, which is general and abstract. The cultivation of students is basically according to standardized products and standards. It is difficult to teach students in accordance with their aptitude for they are from the same production line, which can not guarantee the personnel training quality. There is a big reality needs for talent hierarchical culture. So some domestic scholars also develop the research of the local university personnel training [5] [6]. As base of training high-quality military talents, military academies should be one's unshakable responsibility to assume a large number of innovative talents training tasks needed in the modernization of national defense and the army. As the Central Military Commission institutions directly under the Party Central Committee, the National University of Defense Technology was given one of its mission by the Central Military Commission to train advanced science and engineering and technical personnel and command talents for the army. So the school undertakes the responsibility to train excellent talents for the modernization of national defense and the army. The major initiatives of school's deepening teaching reform and improving the quality of talent cultivation is to open "Tsien Hsueshen innovation class", which can explore and practice talent hierarchical training. This is bold exploration for the cultivation of creative talents.

\section{Investigation and analysis}

\section{A. The Basic Situation of Tsien Hsueshen Innovation Class}

The Ministry of Education and the Organizing Department of the CPC started the 
implementation of the test plan to cultivate top students in basic discipline after twenty-first century. 19 universities including Tsinghua University were pilots to establish the test area for cultivating top students in basic discipline and to explore the way to cultivate individualized talent in learning education center. In order to meet the needs for constructing information army and winning the information war, providing first-class talent and intelligence support to improve combat capability of military system, speeding up the course of creating world-class university of National University of Defense Technology, the school actively carried out teaching reform and innovation, and constantly improved the top-notch innovative talents training system. By the end of 2009, the National University of Defense Technology began brewing company "Tsien Hsueshen innovation class". A small amount of outstanding undergraduate students were selected. The personalization training program was formulated. The training system was not only with the implementation of the special supporting policies, but also with the integration of high quality educational resources. First-class teachers and teaching conditions were equipped to build an international training platform to train top-notch innovative talents with international vision and the potential of leading national defense science and technology for national development and national defense construction. At the same time, through the demonstration effect of "Tsien Hsueshen innovation class", the reform of undergraduate teaching was led and the model of talent cultivation was innovated. These will promote the culture of quality to achieve a new leap of undergraduate talents. The first "Tsien Hsueshen innovation class" began to teach in October of 2010[7]. At present, "Tsien Hsueshen innovation class" has recruited two trainees. Each recruits 30 people and there are 59 members in total(1 was screened out and flowing back to original registration College). According to the training plan of "Tsien Hsueshen innovation class", small class teaching was carried out for student of "Tsien Hsueshen innovation class" in the first two years in order to strengthen public basic courses. The professional courses were learned after returning to their registered institutions with other students in the later two years.

\section{B.Investigation and Analysis}

For a deeper understanding of "Tsien Hsueshen innovation class" with other students on the hierarchical culture and the cultivation of innovative ability and the basic situation, the research was carried out for the students of "Tsien Hsueshen innovation class" and other four Corps cadets (technology and command classes students). The students include 30 people of freshmen and sophomores from "Tsien Hsueshen innovation class", 30 from technical class and 50 from command class. 59 questionnaires were extended for "Tsien Hsueshen innovation class". 55 answers were recycling and the recovery rate was 93.2\%. Among them 1 was invalid questionnaire and the other 54 were valid questionnaires. A total of 200 questionnaires of technology and the command class students were issued. 176 answers were recycling and the recovery rate was $88 \%$. Among them 24 were invalid questionnaires and the other 152 were valid questionnaires.

1、 The view for hierarchical training talents

There are the views from students about the hierarchical training talents of "Tsien Hsueshen innovation class". The survey results show that the students of "Tsien Hsueshen innovation class" were with a high degree of the model. 98.31\% of the students approved or recognized "Tsien Hsueshen innovation class" training model and only 1.69\% of the students said "less adaptation". At the same time, more than $90 \%$ of the students admitted that living and learning experience in "Tsien Hsueshen innovation class" will broaden the way to become talents. 53.29\% students from technologies and command class approve that hierarchical teaching has good effect. 21.05\% students of them do not think so. 9.21\% consider that there is no difference. $16.45 \%$ are not too clear. Hierarchical teaching fundamentally reflect the educational philosophy of talent cultivation based on hierarchical teaching of students in accordance with their aptitude. According to the results of the survey, taking all the survey participants into consideration, 65.88\% students approve the stratified teaching model, which proves that most of the students accept the hierarchical talents training model .

2、 Understanding of their own creativity and innovation incentive factors

The spirit of innovation is always the focus of personnel training, which is the emphasis for 
cultivating top-notch talents of "Tsien Hsueshen innovation class". Therefore, we are dedicated to examining these two aspects of students for innovative spirit and innovative incentive factors.

The students of "Tsien Hsueshen innovation class" are more confident of their innovative ability . More than 87\% students of "Tsien Hsueshen innovation class" think that they are more innovative than ordinary students by $14 \%$. But even in the "Tsien Hsueshen innovation class", there are still $12.96 \%$ students do not know exactly having the spirit of innovation or not. They are almost the same as other students. In the aspect of the incentives to innovate, it can be seen from figure 3 that the exchange of learning opportunities is their enthusiasm for innovation incentive factors that can inspire the students. This reflects students desire and cherish the opportunities of exchanging and learning . Secondly, the "others' ratification" can stimulate students learning and innovation. Compared with the ordinary students, students of "Tsien Hsueshen innovation class" regard "others' ratification" more important . This shows that the incentive effect not only depends on the incentive factors, but is closely related with the incentive object. According to the characteristics of incentive objects in different ways, incentives can have good effect, which is undoubtedly a useful inspiration for managers. Effects of other factors are the highest honor, material incentives and other factors in turn.

3、 The field needing strengthening and improvement for students of "Tsien Hsueshen innovation class"

All the students of "Tsien Hsueshen innovation class" think that they lack some or more aspects of ability. These abilities include the humanistic quality, military quality, academic knowledge, practical ability and innovative spirit. One needing to be strengthened most is humanistic literacy, because there are more than $60 \%$ students who think they need to strengthen. Secondly it is the innovation ability. Although the $87.04 \%$ students think that they have the spirit of innovation, at the same time, $53.07 \%$ of the students think that their own innovation ability still needs to strengthen. There are $57.41 \%$ of the students who think they need to strengthen the hands-on ability.

About the field for supporting and improving of "Tsien Hsueshen innovation class", 55.56\% students choose to provide innovative practice and communicating opportunities, and the other 22.22\% students want to optimize the curriculum and teacher equipment. In the "Tsien Hsueshen innovation class" proposals, $85 \%$ of the students hope to improve the curriculum and the main demand is to streamline the curriculum and deepening the study. At the same time, many students want to reduce the academic burden, which will make students have more energy to take part in all kinds of innovation practice activities of their own interests which will help promote their own training of innovation ability.

\section{Conclusions and suggestions}

It takes ten years to grow trees but a hundred years to rear people. 30 years after "the juvenile class" of University of Science and Technology of China was founded, the vice president Cheng Yi, after interviewing the first batch of graduates, said that education has strongly lagged behind and the success of education needs a long time of accumulation and test. The evaluation of education should pay more attention to using the statistical method. We should not negate the whole because one fails nor should we be pleased because one becomes talent. He thinks that to establish a consistent new way of training, we must obey law of education development, absorb and learn from others' experiences, practice seriously and explore continually[8].

The hierarchical training model is in accordance with talent development objective law and actual demand. This paper research results also support this view. But the talent training is a long-term systematic project. Especially the aim of "Tsien Hsueshen innovation class" is to cultivate the talented persons with international vision and the potential of leading national defense science and technology, which needs several generations decades of long-term persistence and efforts to achieve success. Therefore, it should be based on long-term and in-depth study of the law of education to innovate the model of talent cultivation. The talent level training should be actively 
explored. Moreover we should deepen the education reform, optimize the curriculum and teacher team, strengthen the training of students' practical ability and humanistic quality and improve the incentive elimination mechanism. We should continue to improve the mechanism of talent cultivation, offer students more advantageous polices and provide more protection for teaching, working and living conditions to create a better living and learning conditions for students. The "Tsien Hsueshen innovation development class" should be unswervingly managed well .

\section{Acknowledgment}

Project research fund of 2013 Hunan Provincial Education Teaching: Military civil engineering major education "three in one" model research and Practice; Research on education of 2012 NUDT: Research and practice of talent cultivation model in military civil engineering major.

\section{References}

[1] Z. Lanling and L. De, “The intellectuals of new era,” Jiangxi Social Science, vol. 10, pp.97-99 , 2002.

[2] UNESCO International Commission on the development of education, A comparative study of the translation of the East China Normal University, Learn to Survive - the World of Education Today and Tomorrow [M], Education Science Press, June 1996.

[3] Z. Wenyan, "Study on the theory and practice of small class teaching," Northeast Normal University master's degree thesis [D], vol.5, pp.6, 2008.

[4] P. Haizu and Y. Jianxin, "Research on the example education based on the theory of hierarchical education,” Studies in Ideological Education, vol.11, pp.88-91, 2011.

[5] H. Jiewang, "Stratification of higher education and talent training," University Education in Science, vol.1, pp.98-100, 2007.

[6] C. Yin and S. Xiaojin, "Homework personnel training mode of elastic type "4+2" layered modules,” Jiangsu Higher Education, vol.5, pp.83-84, 2010.

[7] "Tsien Hsueshen innovation development class": fertile ground for training top-notch innovative personnel, http://www.gfkd.mtn /htdocs/ArticleS how. asp?ArticleID=33830

[8] Interpretation of the juvenile class: opportunity model achievement - Section vice president Cheng $\mathrm{Yi}$ described the thoughts and experiences of the juvenile class education. http://wenku.baidu. com/view/abd27e4f2b160b4e767fcf95.html. 